\title{
Household characteristics as predictors of access to paediatric malaria treatment in Homa-Bay County, Kenya
}

\author{
Maurice O. Kodhiambo ${ }^{1 *} \mathbb{D}$, Beatrice K. Amugune ${ }^{2}$ and Julius O. Oyugi ${ }^{3}$
}

\begin{abstract}
Objective: To investigate the influence of socioeconomic household characteristics on access to paediatric malaria treatment in Homa Bay County, Kenya.

Results: From univariate analysis, treatment with analgesics only in a community health center or a faith-based organization, self-employment, urban residence and residing in a sub-county other than Suba or Mbita showed significant association with access to paediatric antimalarial treatment. However, on multivariate analysis, urban residence, education, income of 10,000 to 30,000 and information from peers were the most statistically significant predictors of access to treatment. Urban households were 0.37 times more likely to access treatment than rural ones. Having primary, secondary or post-secondary education conferred $0.25,0.14$ and 0.28 higher chance of access to paediatric malaria treatment respectively compared to those with no formal education. Those with monthly income levels of 10,000 to 30,000 shillings had 0.32 higher chance of accessing treatment compared to those with less than 5000 shillings.
\end{abstract}

Keywords: Household, Access, Paediatric malaria, Homa-Bay

\section{Introduction}

Children in the tropics bear the greatest burden of malaria. Household level access to antimalarial treatment for children with malaria varies greatly from one country to another. For example, a study in four African countries indicated access ranging from $3.6 \%$ for Ethiopia to $64.5 \%$ for Uganda. Those who accessed the artemisinin combination therapy (ACT) varied from 32.2\% in Zambia and almost $100 \%$ in Tanzania [1]. Apart from knowledge, socio-economic factors such as having health insurance, ability to pay for care, positive attitude and perceived social support have also been associated with prompt access to malaria treatment [2]. Having medical insurance and distance traveled to health facility has generally been associated with health demand [3]. From a study in Burkina Faso, possession of antimalarial drugs at the

\footnotetext{
*Correspondence: olejioni@gmail.com

1 School of Pharmacy, Kenyatta University, P.O. Box 43844-00100, Nairobi, Kenya

Full list of author information is available at the end of the article
}

households was associated with urban residence, level of education of household head, having young children, and high socio-economic status [4]. These findings thus show that differences in political and health policy characteristics between countries may be important in enabling households to access treatment. In Kenya, it is empirically documented that household size, household head, income source, amount of monthly income and age of the household head significantly influence access to care [5]. It is however not yet clear to what extent the new policy of health care service devolution in Kenya has impacted on access to malaria care. The study set out to investigate the association between household characteristics access to paediatric malaria treatment in Homa Bay County, Kenya after implementation of devolution of healthcare.

\section{Main text \\ Study design and settings}

The study was conducted as a population-based survey. Data was collected from household heads within their households between August 2016 and May 2017. 
The study was carried out in Homa Bay County which is located around the shores of Lake Victoria in Western Kenya. It is approximately $400 \mathrm{~km}$ South West of the Kenyan capital city, Nairobi.

\section{Study participants}

The study population comprised all household heads in the eight sub-Counties of Homa-Bay County, Kenya. Data was collected from household heads as identified by the members of the household present during data collection. The decision to interview the household head only was arrived at baseline survey when we realized that most of the households in this rural County were headed by authoritarian males. Ignoring their power in household decisions would therefore have jeopardized our study as they would take it as insubordination. If the household head was absent, the household was skipped for the net until the sample size is attained.

\section{Sampling}

Homa-Bay County was divided into blocks of eight subcounties. Each block was further divided into urban and rural sub-blocks. For each of the sub-blocks, a sub-location was randomly sampled by way of cluster sampling. From each sub-location, a simple random sample of 20 households for rural and 30 households for urban clusters was taken. The sample size was therefore 16 clusters. All the households in each of the clusters sampled were included in the study. Ten percent of the sample size was added to cater for non response making the total sample size to be 440 . Those that responded were 406 , representing $92.3 \%$ response rate.

\section{Data collection tool and procedure}

Research assistants arrived in a household, introduced themselves and requested the head of the household to either read the consent explanation or have it read to them before consenting. Upon granting the consent, the questionnaire was administered to them. Data collection was based on verbal autopsy and not on prescriptions or treatment records. This was because prescriptions and treatment records are often not available at the household level in Kenya. The questionnaire was designed to exclude culture sensitive questions such as household size and number of children in the household. In the culture of the rural Luo community, it is believed that if you count children, they will die soon in the order they are counted. We thought it was ethical to respect the culture of the respondents.

\section{Statistical analyses}

Data was collected then cleaned, sorted and coded before entering on an excel spreadsheet followed by analysis by the $\mathrm{R}$ statistical software. General descriptive statistics analysis was performed prior to logistic regression to elicit the predictors of access to malaria treatment. Odds ratios and p-values we generated to assist in the analysis. The p-values were considered significant at the level of 0.05 .

\section{Confounders}

Potential confounders such as age and sex of household head as well as having medical insurance were recorded at the baseline interview prior to the survey.

\section{Results}

\section{Access to paediatric malaria treatment at the household} level

For those respondents that reported that their child had a malaria symptom within 1 month prior to the survey, several questions were posed to assess the level of access to malaria treatment. The results of the descriptive analysis of the responses are captured in Table 1.

\section{Association between household characteristics and access to paediatric malaria treatment}

The potential predictors of access were subjected to univariate analysis of how they individually regressed on household access to paediatric malaria treatment. A summary of the findings is as presented in Table 2.

From the univariate analysis, the predictors that showed statistically significant association with access to paediatric malaria treatment were seeking care from a community health center $\mathrm{OR}=5.21 \quad(1.06-$ 25.68) $(\mathrm{p}=0.025)$, and from a faith-based organization $(\mathrm{OR}=3.22 \quad(1.18-8.81) \quad(\mathrm{p}=0.017)$. Other factors that were statistically significant were self-employment $\mathrm{OR}=0.49(0.24-1.00) \quad(\mathrm{p}$-value $=0.046)$, living in an urban area of Homa-Bay County OR $=0.39(0.25-0.59)$ $(\mathrm{p}<0.001)$, and being a resident of Kabondo OR $=0.44$ $(0.19-1.01) \quad(\mathrm{p}=0.049)$, Kasipul OR=0.06 $(0.02-0.17)$ $(\mathrm{p}<0.001), \quad$ Ndhiwa $\mathrm{OR}=0.11 \quad(0.04-0.28) \quad(\mathrm{p} \leq 0.001)$, Rangwe OR $=0.14(0.47-2.79)(\mathrm{p} \leq 0.001)$ or Rachuonyo $\mathrm{OR}=0.12(0.04-0.28)(\mathrm{p} \leq 0.001)$ sub-counties.

All the predictors were then subjected to multiple regression analysis using the R-Studio software. Results of the multivariate logistic regression analysis are shown in Table 3.

On multivariate analysis, urban residence, education at all levels, monthly household income of 10,000 to 30,000 and information from friends stood out as the most statistically significant predictors of access to paediatric malaria treatment in Homa-Bay County. 
Table 1 Access to paediatric malaria treatment by the households

\begin{tabular}{|c|c|c|}
\hline Characteristics & Frequency & $\%$ \\
\hline \multicolumn{3}{|c|}{ Child had malaria symptoms in the past month } \\
\hline Yes & 371 & 91.4 \\
\hline No & 35 & 8.6 \\
\hline \multicolumn{3}{|c|}{ Severity of malaria symptoms when child was sick } \\
\hline Not serious & 86 & 21.2 \\
\hline Very serious & 320 & 78.8 \\
\hline \multicolumn{3}{|l|}{ Medicines available at home } \\
\hline None & 216 & 53.2 \\
\hline ACT and analgesics & 5 & 1.3 \\
\hline ACT only & 78 & 19.2 \\
\hline Analgesic only & 7 & 1.7 \\
\hline Other medicines & 100 & 24.6 \\
\hline \multicolumn{3}{|l|}{ Drugs prescribed on visit } \\
\hline ACT only & 170 & 41.9 \\
\hline Antibiotic only & 8 & 2.0 \\
\hline $\mathrm{ACT}+$ antibiotic & 17 & 4.2 \\
\hline $\mathrm{ACT}+$ analgesic & 43 & 10.6 \\
\hline $\mathrm{ACT}+$ other antimalarials & 11 & 2.7 \\
\hline Non-ACT antimalarial & 80 & 19.7 \\
\hline Analgesic only & 31 & 7.6 \\
\hline Do not know & 46 & 11.3 \\
\hline \multicolumn{3}{|c|}{ Was blood drawn for diagnosis of malaria? } \\
\hline Yes & 310 & 76.4 \\
\hline No & 62 & 15.0 \\
\hline Not sure & 34 & 8.6 \\
\hline \multicolumn{3}{|c|}{ If the diagnosis was done what was the result } \\
\hline Positive & 207 & 51.0 \\
\hline Negative & 103 & 25.4 \\
\hline Can't remember & 96 & 23.6 \\
\hline \multicolumn{3}{|l|}{ Opinion on treatment cost } \\
\hline Affordable & 199 & 49.0 \\
\hline Not affordable & 207 & 51.0 \\
\hline \multicolumn{3}{|c|}{ Availability of anti-malarial drugs } \\
\hline Regularly available & 166 & 40.9 \\
\hline Not regularly available & 240 & 59.1 \\
\hline
\end{tabular}

\section{Discussion}

The prevalence of malaria among children with fever one month prior to the study was $66.8 \%$. This percentage is much higher than that estimated in a study in Maiduguri city [6]. This is possibly due to incorrect or inconsistent use of the bed nets. Even if they used them consistently, it was also evident that they were treated with mosquito repellants only intermittently. However, there is also a possibility of over diagnosis which has been shown to be common in malaria endemic areas
[7]. Government owned health care facilities were most preferred as the first place for seeking care. Time lapse between onset of symptoms and seeking treatment was significantly associated with education and occupation of the head of the household, severity of illness, having medicines at the household, income and residence. Similar findings were reported by Kassile et al. [8] and Angwin et al. [9]. They stated that delays in care seeking for children with fever was determined by communal beliefs, socio-economic status, education and occupation of household head. Tipke et al. [4] also found out that having drugs at the household usually delays care seeking. In Africa, most caregivers prefer to manage childhood fevers at home or to seek folklore medicines before going for conventional treatment $[2,3,10]$. Perhaps they do so because as much as they may be physically able to access care, financial barriers do exist. There are three universally accepted dimensions of access to health care namely availability, acceptability and affordability. In this study, we operationally defined access as both physical and financial ability to utilize health care. From univariate regression, access to malaria care was associated with medicine prescribed, seeking initial care from a community health centre or FBO, self employment, urban residence and sub-county. However, on multivariate analysis, access was found to be statistically significantly associated only with education, income, residing in an urban neighbourhood and receiving information about malaria from peers. Researchers in Rwanda reported similar findings that access to malaria treatment is associated with knowledge and socio-economic status of the household head as well as social support [2]. We considered receiving information on malaria from peers as an indicator of having social support. Perceptions about treatment outcomes were associated with visiting a government health facility, urban residence and being self-employed. These findings concur with those of a study in Tanzania which reported that people who were financially more stable preferred government health facilities as they were associated with better outcomes [11]. Similar findings were recorded from a Burkinabe [12] where treatment outcomes were associated with residence, education and socio-economic status of the household head, delay in initiating treatment and home based care. Some participants reported to have been given only ACT. This was probably because they informed the clinician that they had the other medicines at home. Alternatively there could have been drug stock outs for the other medicines, which is a frequent phenomenon in rural Kenya even for the most essential of drugs. 
Table 2 Univariate analysis of predictors of household access to paediatric malaria treatment

\begin{tabular}{|c|c|c|c|c|}
\hline \multirow[t]{3}{*}{ Characteristics } & \multicolumn{4}{|l|}{ Access } \\
\hline & Accessible & Inaccessible & OR $(95 \% \mathrm{Cl})$ & P-value \\
\hline & n (\%) & n (\%) & & \\
\hline \multicolumn{5}{|l|}{ Drugs given } \\
\hline Antibiotic only & $6(2.8)$ & $2(1.1)$ & 1 & \\
\hline $\mathrm{ACT}+$ anti-biotics & $8(3.6)$ & $9(4.8)$ & $3.38(0.52-21.73)$ & 0.189 \\
\hline $\mathrm{ACT}+$ analgesic & $25(11.5)$ & $18(9.6)$ & $2.16(0.39-11.95)$ & 0.369 \\
\hline $\mathrm{ACT}+$ other anti-malarial & $4(1.8)$ & $7(3.7)$ & $5.25(0.69-39.48)$ & 0.096 \\
\hline ACT only & $118(54.4)$ & $52(27.5)$ & $1.32(0.26-6.77)$ & 0.737 \\
\hline Analgesic only & $9(4.1)$ & $22(11.6)$ & $7.33(1.24-43.41)$ & 0.017 \\
\hline Non-ACT anti-malarial & $21(9.7)$ & $59(31.2)$ & $8.43(1.58-45.05)$ & 0.004 \\
\hline Cannot remember & $26(12.0)$ & $20(10.5)$ & $1.02(0.53-1.34)$ & 0.560 \\
\hline \multicolumn{5}{|l|}{ Was blood drawn for diagnosis? } \\
\hline Yes & $172(78.2)$ & $138(74.2)$ & 1 & \\
\hline No & $27(12.3)$ & $35(18.8)$ & $1.62(0.93-2.80)$ & 0.085 \\
\hline Cannot remember & $21(9.5)$ & $13(7.0)$ & $1.55(0.87-2.41)$ & 0.096 \\
\hline \multicolumn{5}{|l|}{ Where did you seek care } \\
\hline Government hospital & $128(61.0)$ & $86(41.7)$ & 1 & \\
\hline Private hospital & $19(9.0)$ & $20(9.7)$ & $1.57(0.79-3.11)$ & 0.197 \\
\hline Pharmacy & $17(8.1)$ & $16(7.8)$ & $1.40(0.67-2.92)$ & 0.368 \\
\hline Community Health Centre & $2(1.0)$ & $7(3.3)$ & $5.21(1.06-25.68)$ & 0.025 \\
\hline Shop & $17(8.1)$ & $11(5.3)$ & $0.96(0.43-2.16)$ & 0.927 \\
\hline Traditional practitioner & $8(3.7)$ & $11(5.3)$ & $2.05(0.79-5.29)$ & 0.133 \\
\hline Other & $2(1.0)$ & $8(3.9)$ & $5.95(1.23-28.71)$ & 0.126 \\
\hline Faith Based Org. (FBO) & $6(2.9)$ & $13(6.3)$ & $3.22(1.18-8.81)$ & 0.017 \\
\hline Not sure & $11(5.2)$ & $24(11.7)$ & $4.31(0.82-6.34)$ & 0.71 \\
\hline \multicolumn{5}{|l|}{ Occupation } \\
\hline Business & $15(6.8)$ & $21(11.2)$ & 1 & \\
\hline Farmer & $32(14.6)$ & $42(22.5)$ & $0.94(0.42-2.10)$ & 0.875 \\
\hline Salaried employment & $27(12.3)$ & $25(13.4)$ & $0.66(0.28-1.56)$ & 0.344 \\
\hline Self employed & $125(57.1)$ & $85(45.4)$ & $0.49(0.24-1.00)$ & 0.046 \\
\hline No response & $20(9.2)$ & $14(7.5)$ & 0.73 & 0.512 \\
\hline \multicolumn{5}{|l|}{ Household status } \\
\hline Rural & $55(26.6)$ & $86(42.3)$ & 1 & \\
\hline Urban & $144(69.6)$ & $87(43.7)$ & $0.39(0.25-0.59)$ & $<0.001$ \\
\hline No response & $8(3.8)$ & $26(13.0)$ & $0.93(0.62-1.26)$ & 0.077 \\
\hline \multicolumn{5}{|l|}{ Sub-County } \\
\hline Homabay & $14(6.5)$ & $33(17.5)$ & 1 & \\
\hline Kabondo & $26(12.0)$ & $27(14.3)$ & $0.44(0.19-1.01)$ & 0.049 \\
\hline Kasipul & $42(19.4)$ & $6(3.2)$ & $0.06(0.02-0.17)$ & $<0.001$ \\
\hline Mbita & $7(3.2)$ & $44(23.3)$ & $2.67(0.96-7.35)$ & 0.053 \\
\hline Ndhiwa & 36 (16.6) & $9(4.7)$ & $0.11(0.04-0.28)$ & $<0.001$ \\
\hline Rangwe & $30(13.8)$ & $10(5.3)$ & $0.14(0.47-2.79)$ & $<0.001$ \\
\hline Suba & $13(6.0)$ & 35 (18.5) & $1.14(0.47-2.79)$ & 0.770 \\
\hline Rachuonyo & $31(14.2)$ & $9(4.8)$ & $0.12(0.05-0.33)$ & $<0.001$ \\
\hline No response & $18(8.3)$ & $16(8.4)$ & $1.54(0.79-1.55)$ & 0.063 \\
\hline
\end{tabular}


Table 3 Multiple logistic regression analysis of predictors of Household access to paediatric malaria treatment

\begin{tabular}{|c|c|c|c|c|}
\hline Predictor & Coeff. & OR & $95 \% \mathrm{Cl}$ & $\mathrm{p}$-value \\
\hline \multicolumn{5}{|l|}{ Place of residence } \\
\hline Urban & 0.997 & 0.37 & $(-1.516,-4.780)$ & $<0.001$ \\
\hline \multicolumn{5}{|l|}{ Education } \\
\hline Primary & 1.396 & 0.25 & $(-2.411,-0.380)$ & 0.007 \\
\hline Secondary & 1.969 & 0.14 & $(-3.001,-0.932)$ & $<0.001$ \\
\hline Post-secondary & 1.291 & 0.28 & $(-2.466,-0.114)$ & 0.032 \\
\hline \multicolumn{5}{|l|}{ Occupation } \\
\hline Farming & 0.609 & 0.54 & $(-1.643,0.424)$ & 0.248 \\
\hline Salaried employment & 0.300 & 0.74 & $(-1.312,0.713)$ & 0.562 \\
\hline Self-employment & 0.608 & 0.54 & $(-1.499,0.284)$ & 0.181 \\
\hline \multicolumn{5}{|l|}{ Monthly income (Kshs) } \\
\hline $5000-10,000$ & 0.197 & 0.82 & $(-1.771,0.380)$ & 0.502 \\
\hline $10,000-3,0000$ & 1.147 & 0.32 & $(-2.139,-1.554)$ & 0.023 \\
\hline $30,000-50,000$ & 0.584 & 1.79 & $(-0.478,1.647)$ & 0.281 \\
\hline$>50,000$ & 0.515 & 1.67 & $(-1.813,-0.843)$ & 0.447 \\
\hline \multicolumn{5}{|c|}{ Source of information on malaria } \\
\hline Peers & 2.930 & 18.736 & $(0.825,5.036)$ & 0.006 \\
\hline Hospital & 1.625 & 5.079 & $(-0.102,3.353)$ & 0.065 \\
\hline Media & 1.385 & 4.000 & $(-0.325,-3.096)$ & 0.112 \\
\hline Pharmacy & 1.603 & 4.968 & $(-0.383,-3.589)$ & 0.114 \\
\hline Public health officers & 0.667 & 1.948 & $(-1.191,-2.525)$ & 0.482 \\
\hline \multicolumn{5}{|l|}{ Time to care seeking } \\
\hline Delayed & -0.351 & 0.704 & $(-0.848,0.146)$ & 0.116 \\
\hline
\end{tabular}

\section{Conclusion}

The findings of this study provide sufficient scientific evidence that socioeconomic status and level of education of the household head, rural or urban residence and perceived social support are key predictors of household access to paediatric malaria treatment in Homa Bay County. Further research should probe on how these factors affect the overall health systems performance.

\section{Limitations}

This study was conducted as a cross sectional survey thus making it difficult to ascertain a causal relationship between the exposure and outcome. Only associations may be inferred. Additionally, since all data was collected by way of respondent reports, there is a possibility of recall bias.

\section{Abbreviation}

ACT: artemisinin combination therapy.

\section{Authors' information}

MOK is a Doctoral Student at the University of Nairobi Institute of Tropical and Infectious Diseases (UNITID), under the supervision and mentorship of BKA and $\mathrm{JOO}$ both of whom are senior lecturers in the College of Health Sciences of the University of Nairobi.

\section{Acknowledgements}

We wish to acknowledge the statistician, Dr. Alex Mwaniki for his assistance with the conceptualisation of the study design and data analysis.

\section{Authors' contributions}

MOK, BKA and JOO participated in the conceptualization and design of the study. MK collected and analyzed the data, interpreted the data and drafted the manuscript. MOK, BKA and JOO revised the manuscript and gave final approval of the version to be published. MOK, BKA and JOO accept to be responsible for all aspects of the study committing to ensure that questions related to the accuracy or integrity of any part of the work are investigated and resolved within a reasonable time frame. All authors read and approved the final manuscript.

\section{Funding}

There is no funding to declare. The data collection and analysis were facilitated with the resources of the corresponding author.

\section{Availability of data and materials \\ All the necessary data are presented herewith. However if needed, raw data on excel format can be availed on reasonable request from the corresponding} author.

\section{Ethics approval and consent to participate}

Data safety and confidentiality was ensured by restricting access and using backups. Research authorisation was obtained from the Kenyatta National Hospital/University of Nairobi-Ethics and Research Committee (RefP389/05/2016). Permission was obtained from the County Director of Medical Services (CDMS) prior to data collection. Written voluntary informed consent was obtained from participants before recruitment into the study. The participants were free to leave study at any time without any consequences to them No compensation for participation in the study was done. Confidentiality was ensured by use of codes rather than direct identifiers.

\section{Consent for publication}

Not applicable.

\section{Competing interests}

The authors declare that they have no competing interests.

\section{Author details}

${ }^{1}$ School of Pharmacy, Kenyatta University, P.O. Box 43844-00100, Nairobi, Kenya. ${ }^{2}$ Department of Pharmaceutical Chemistry, University of Nairobi, Nairobi, Kenya. ${ }^{3}$ Department of Medical Microbiology, University of Nairobi, Nairobi, Kenya.

Received: 8 April 2019 Accepted: 24 July 2019

Published online: 07 August 2019

References

1. Shah JA, Emina JB, Eckert E, Ye Y. Prompt access to effective malaria treatment among children under five in sub-Saharan Africa: a multi-country analysis of national household survey data. Malar J. 2015;14:329. https:// doi.org/10.1186/s12936-015-0844-7.

2. Ingabire CM, Kateera F, Hakizimana E, Rulisa A, Muvunyi C, Mens P, Koenraadt CJ, Mutesa L, Van Vugt M, Van Den Borne B, Alaii J. Determinants of prompt and adequate care among presumed malaria cases in a community in eastern Rwanda: a cross sectional study. Malar J. 2016;15:227. https ://doi.org/10.1186/s12936-016-1285-7.

3. Fenny AP, Asante FA, Enemark U, Hansen KS. Malaria care seeking behavior of individuals in Ghana under the NHIS: are we back to the use of informal care? BMC Public Health. 2015;15:370. https://doi.org/10.1186/ s12889-015-1696-3.

4. Tipke M, Louis VR, Yé M, De Allegri M, Beiersmann C, Sié A, Mueller O, Jahn A. Access to malaria treatment in young children of rural Burkina Faso. Malar J. 2009;8:266. https://doi.org/10.1186/1475-2875-8-266. 
5. Watsierah CA, Jura WG, Oyugi H, Abong'o B, Ouma C. Factors determining anti-malarial drug use in a peri-urban population from malaria holoendemic region of western Kenya. Malar J. 2010;9:295.

6. Elechi HA, et al. Prevalence and pattern of malaria parasitaemia among under-five febrile children attending paediatric out-patient clinic at University of Maiduguri Teaching Hospital, Maiduguri. Niger J Paediatr. 2015;42(4):319-24.

7. Orish VN, Ansong JY, Onyeabor OS, Sanyaolu AO, Oyibo WA, Iriemenam NC. Overdiagnosis and overtreatment of malaria in children in a secondary healthcare center in Sekondi-Takoradi, Ghana. Trop Dr. 2016;46:191-8.

8. Kassile T, Lokina R, Mujinja P, Mmbando BP. Determinants of delay in care seeking among children under five with fever in Dodoma region, central Tanzania: a cross-sectional study. Malar J. 2014;13:348.

9. Angwin A, Hetzel MW, Mueller I, Siba PM, Pulford J. A qualitative study of how affected individuals or their caregivers respond to suspected malaria infection in rural Papua New Guinea. P N G Med J. 2014:57(1-4):30-8.
10. Kassam R, Sekiwunga R, Collins JB, Tembe J, Liow E. Caregivers'treatmentseeking behaviors and predictors of whether a child received an appropriate antimalarial treatment: a household survey in rural Uganda. BMC Infect Dis. 2016;16:478.

11. Simba D, Kakoko D. Access to subsidized artemether-lumefantrine from the private sector among febrile children in rural setting in Kilosa, Tanzania. Tanzan J Health Res. 2012;14(2):89-95.

12. Zoungrana A, Chou YJ, Pu C. Socioeconomic and environment determinants as predictors of severe malaria in children under 5 years of age admitted in two hospitals in Koudougou district, Burkina Faso: a cross sectional study. Acta Trop. 2014;139:109-14.

\section{Publisher's Note}

Springer Nature remains neutral with regard to jurisdictional claims in published maps and institutional affiliations.
Ready to submit your research? Choose BMC and benefit from:

- fast, convenient online submission

- thorough peer review by experienced researchers in your field

- rapid publication on acceptance

- support for research data, including large and complex data types

- gold Open Access which fosters wider collaboration and increased citations

- maximum visibility for your research: over $100 \mathrm{M}$ website views per year

At BMC, research is always in progress.

Learn more biomedcentral.com/submissions 